\title{
Relationship between annealing time and magnetic properties in Bi-2212 textured composites
}

\author{
B. Özçelik ${ }^{\mathrm{a}^{*}}$, B. Özkurt ${ }^{\mathrm{b}}$, M.E. Yakıncı ${ }^{\mathrm{c}}$, A. Sotelo ${ }^{\mathrm{d}}$, M. A. Madre ${ }^{\mathrm{d}}$ \\ ${ }^{a}$ Department of Physics, Faculty of Sciences and Letters, Çukurova University. 01330 \\ Adana, Turkey \\ ${ }^{\mathrm{b}}$ Department of Electronic and Computer Education, Faculty of Tarsus Technical \\ Education, University of Mersin, Mersin/Turkey \\ ${ }^{c}$ Department of Physics, Faculty of Sciences and Letters, Inönü University. 44069 \\ Malatya, Turkey \\ d ICMA (CSIC-Universidad de Zaragoza). María de Luna, 3. 50018 Zaragoza, Spain.
}

\begin{abstract}
In this study, we report the physical and magnetic properties of $\mathrm{Bi}_{2} \mathrm{Sr}_{2} \mathrm{CaCu}_{2} \mathrm{O}_{\mathrm{x}}$ textured materials prepared by a LFZ melting technique and annealed for different times $(60,72$, 96 and 120 h). SEM images of the annealed samples for 96 and 120 hours indicate very good alignment with the longitudinal rod axis. In all cases, X-ray diffraction patterns show that the $\mathrm{Bi}-2212$ phase is the major one. The magnetization measurements have been carried out as a function of the magnetic field up to $9 \mathrm{kOe}$. $\mathrm{J}_{\mathrm{c}}$ values of the samples were calculated by using the Bean's model. The results indicate that the different annealing time has no significant effects on the $T_{c}$ values but, significant change on the critical current values of samples, $\mathrm{J}_{\mathrm{c}}$, has been obtained for sample annealed at 96 hours. We also found that the maximum critical density of $\mathrm{J}_{\mathrm{c}}$ is $5.5 \times 10^{5} \mathrm{~A} / \mathrm{cm}^{2}$ at $10 \mathrm{~K}$ for the 96 hours annealed sample.
\end{abstract}

Keywords: Bi-2212 $\cdot$ LFZ technique $\cdot$ Magnetic Properties $\cdot$ Critical Current density $\left(\mathrm{J}_{\mathrm{c}}\right)$

* Corresponding author. Tel.: +90 322 3386060/2496; fax: +90 3223386070 e-mail: ozcelik@cu.edu.tr 


\section{INTRODUCTION}

Since the discovery of superconductivity in the Bi-Sr-Cu-O system by Michel et al. [1] and the subsequent work reported by Maeda et al. [2] in $\mathrm{Bi}_{2} \mathrm{Sr}_{2} \mathrm{Ca}_{n-1} \mathrm{Cu}_{\mathrm{n}} \mathrm{O}_{\mathrm{x}}(n=1,2,3)$ superconductor, a lot of work has been made in order to improve the physical properties of BSCCO system. For potential industrial applications such as superconducting wires, tapes and thin films [3-5] it is necessary to produce the $\mathrm{Bi}-2223$ or $\mathrm{Bi}-2212$ as single phase. As a consequence, the synthetic methods have been widely studied to produce high quality samples. Among these preparation techniques, some of them can be underlined, as the classical solid state [6,7] melt quench [8,9], sol-gel [10-13] and the polymer matrix [14-16] methods. Moreover, doping has been also exctensively studied in order to promote the formation of intragranular pinning centers or reduce weak links and, as a consequence, raise the electrical properties of this kind of materials $[17,18]$.

On the other hand, since high temperature superconductors possess a high anisotropy from the crystallographic point of view but also from the transport one. Due to this anisotropy, grain orientation plays an important role on the transport properties, and it is the reason that texturing processes have been widely studied. As a result, when BSCCO materials are properly textured, their transport properties are improved in an important manner, compared with the non-textured materials. The texturing methods can be roughly divided into solid state methods, where the sample, or at least an important part, is maintained as a solid $[19,20]$ and those where the sample is totally molten (directional solidification techniques). Among these last methods, the Laser Floating Zone (LFZ) one has been demonstrated to be an effective technique to produce a good grain orientation not only in Bi-2223 [7,21] and Bi-2212 [22,23] superconductors, but also in other anisotropic systems [24]. This method produces very high thermal gradients in the solidification front, producing a preferential alignment of grains with their c-axis perpendicular to the growth direction [25], maximizing the transport properties in the direction parallel to the growth axis.

As it is well known, BSCCO superconductors show an incongruent melting, which makes necessary to perform annealing processes to produce the superconducting phase after a melt grown process [26]. The control of these annealing parameters would lead to the production of textured superconducting ceramics with high $\mathrm{J}_{\mathrm{c}}$ values together with a high degree of reproducibility. 
In this work, it is presented the effect of annealing time on the formation and superconducting properties of LFZ grown Bi-2212 ceramics.

\section{EXPERIMENTAL}

Bi-2212 polycrystalline ceramics have been prepared, by a polymer matrix route [27,28], from $\mathrm{Bi}\left(\mathrm{CH}_{3} \mathrm{CO}_{2}\right)_{2}$ ( $\geq 99.99 \%$, Aldrich), $\mathrm{Sr}\left(\mathrm{CH}_{3} \mathrm{CO}_{2}\right) \cdot 0.5 \mathrm{H}_{2} \mathrm{O}$ (99\%, Panreac), $\mathrm{Ca}\left(\mathrm{CH}_{3} \mathrm{CO}_{2}\right) \cdot 2 \mathrm{H}_{2} \mathrm{O}$ (98\%, Alfa Aesar), and $\mathrm{Cu}\left(\mathrm{CH}_{3} \mathrm{CO}_{2}\right)_{2} \cdot \mathrm{H}_{2} \mathrm{O}$ (98\%, Panreac) commercial powders. They were weighed in the adequate proportions and dissolved in a mixture of glacial acetic acid $\left(\mathrm{CH}_{3} \mathrm{COOH}\right)$ (Panreac p.a.) and distilled water. The use of a mixture of glacial acetic acid and water is due to the fact that in one side $\mathrm{Sr}$ acetate is insoluble in concentrated acetic acid and, on the other side, Bi acetate is not soluble in water [29].

Once obtained a clear blue solution, polyethylenimine (PEI) (Aldrich, $50 \mathrm{wt} \%$ water) solution in distilled water, in order to reduce the viscosity of commercial PEI, was added. The mixture become dark blue immediately due to the formation of $\mathrm{Cu}-\mathrm{N}$ coordination bonds. The solution was then introduced into a rotary evaporator to reduce its volume $(\sim 80 \%)$ followed by heating on a hot plate at about $100{ }^{\circ} \mathrm{C}$ for total solvent evaporation to produce a thermoplastic dark blue paste. Further heating at around 350 ${ }^{\circ} \mathrm{C}$ produces a decomposition step, as described schematically elsewhere [30]. The resulting powder was then milled in an agate mortar and calcined twice at 750 and $800^{\circ} \mathrm{C}$ for $12 \mathrm{~h}$ in order to decompose the alkaline-earth carbonates in order to avoid the bubbles formation in the melting process.

The prereacted homogeneous powders were used to prepare cylindrical precursors, 120 $\mathrm{mm}$ long and $3 \mathrm{~mm}$ in diameter, approximately, by cold isostatic pressing with an applied pressure of $200 \mathrm{MPa}$ during 1 minute. The obtained cylinders were used as feed in a directional solidification process performed in a laser floating zone melting (LFZ) installation which has been described schematically in previous works [31] and represented in Fig. 1. In this figure, it can be clearly seen:

- the feed, which is moving downwards with fixed feed speed $(24 \mathrm{~mm} / \mathrm{h})$, in order to maintain a constant material supply to the molten zone, and rotation (15 rpm clockwise) to homogeneize the molten zone composition.

- the textured material, which has been firstly solidificated on the seed and is also moving downwards with fixed seed speed $(30 \mathrm{~mm} / \mathrm{h})$, in order to maintain a constant 
material extraction from the molten zone, and rotation ( $3 \mathrm{rpm}$ anticlockwise) to maintain the cylindrical geometry.

- the molten zone, induced by a continuous Nd:YAG laser $(\lambda=1064 \mathrm{~nm})$, which is not moving and its liquid volume is kept constant all along the process.

After growth process, long(more than $20 \mathrm{~cm}$ ) and geometrically homogeneous textured cylindrical rods were obtained. As indicated previously, the Bi-2212 phase melts inconguently and, as a consequence, after the texturing process, the samples were subjected to an annealing process at $850{ }^{0} \mathrm{C}$ for different time lengths, with a final quench in air to room temperature. This annealing has been performed under air to avoid oxygen overdoping which could negatively affect the $T_{c}$ values [32].

In order to identify the present phases in the textured materials, powder X-ray diffraction diagrams of the final products were recorded at room temperature using a Rigaku RadB powder diffractometer system working with $\mathrm{CuK} \alpha$ radiation and a constant scan rate between $2 \theta=3-60^{\circ}$ at room temperature. SEM micrographs were taken using a LEO Evo-40 VPX scanning electron microscope (SEM). Magnetic measurements were carried out in a Cryogenic Q-3398 Vibrating Sample Magnetometer (VSM) system. The samples annealed at $850^{\circ} \mathrm{C}$ for $60,72,96$ and $120 \mathrm{~h}$ will be hereafter named as A, B, C, and D, respectively.

\section{RESULTS AND DISCUSSIONS}

As it has been already reported [33,34], LFZ grown materials show a good alignment of the c-axis nearly perpendicular to the growth direction. This grain orientation induces an important increase on the current transport due to the alignment of the $a b$ planes (the conducting ones) parallel to the growth direction.

In order to study the grain sizes evolution with annealing time, SEM micrographs have been performed on transversal fractured sections of samples and displayed in Fig. 2. As it can be clearly seen in the figure, all samples are composed of plate-like grains, which are the typical feature of the $\mathrm{Bi}-2212$ superconducting phase. Moreover, the grain size is increasing with the annealing time in both thickness and length from sample A to D. This grain growth process, produced by cationic diffusion, lead to a system energy decrease by the disappearing of the small grains and the growth of the big ones. This effect is of the main importance, but it is not the only one, to reduce the number of grain boundaries which usually limit the current transport. 
Another interesting feature which can be observed in the micrographs is that the grains tend to grow with their $a b$ planes parallel each other and this trend is more marked when the annealing time is increased.

Fig. 3 shows the XRD diffraction patterns for the samples annealed for different times where the peaks for the $\mathrm{Bi}-2212$ superconducting phase have been indicated. From these graphs, it can be deduced that $\mathrm{Bi}-2212$ phase is the major one, independently of the annealing time. Moreover, small amounts of $\mathrm{CaBi}_{2} \mathrm{O}_{4}$ nonsuperconducting secondary phase can be detected in the samples. From these data, it is clear that the crystal symmetry of all the samples is tetragonal, with obtained lattice parameters $a=3,825$ and $\mathrm{c}=30,820 \AA$. On the other hand, the XRD patterns are very similar for all the samples with only minor differences in the relative intensity for some diffraction which can be produced by an induced orientation of the plate-like grains in the samples preparation for the XRD diffraction experiments.

The hysteresis curves of the samples have been measured at three different temperatures 10,20 , and $30 \mathrm{~K}$. All those hysteresis loops were obtained after cooling the sample in zero magnetic fields (ZFC) and measured between the fields of \pm 9 Tesla. For clarity, in Fig. 4 it is only shown the magnetic hysteresis curves of samples measured at $10 \mathrm{~K}$, but taking into account that the evolution of the samples has been the same in all the measured temperatures. The general behavior of hysteresis loops shown in this figure indicates that there is a dependence of magnetization values with the annealing time. The magnetization values increase when annealing time is raised, except for sample D which decreases from the values obtained for sample $C$. This is an indication that the superconducting properties start to be negatively affected for annealing times above 96 h. In addition, the volume of the closed hysteresis curves is increased with annealing time in the same way. A large hysteresis curves and high magnetization values lead to high critical current density values. As a consequence, the best properties are reached for sample $\mathrm{C}$.

Fig. 5 shows the magnetization as a function of temperature for all the samples. From this graphic it is clear that the best results are obtained for the sample $\mathrm{C}$, confirming the observations made in the hysteresis loops and discussed previously. In spite of these variations, critical temperature, $T_{c}$, is approximately the same for all the samples. This result indicate that the oxygen content in all the samples is approximately the same, as $\mathrm{T}_{\mathrm{c}}$ is very sensitive to the $\delta$ value in the general formula $\mathrm{Bi}_{2} \mathrm{Sr}_{2} \mathrm{CaCu}_{2} \mathrm{O}_{8+\delta}$ [32]. 
The $\mathrm{J}_{\mathrm{c}}$ values of the samples were calculated from the hysteresis loop data obtained at three different temperatures, 10, 20 and $30 \mathrm{~K}$, using the Bean's model [35]

$$
\mathrm{J}_{\mathrm{c}}=30 \frac{\Delta M}{d}
$$

where $\mathrm{J}_{\mathrm{c}}$ is the magnetization current density in ampéres per square centimeter, $\Delta M=$ $M_{+}-M_{-}$is measured in electromagnetic units per cubic centimeter, and $d$ is the thickness of sample.

Fig. 6 shows the calculated $J_{c}$ values for all the samples at $10 \mathrm{~K}$. In this figure, it can be clearly seen that $J_{c}$ values increase with annealing time, independently of the external applied field until the maximum values are achieved for sample $\mathrm{C}$, and decreasing for sample D. The reason for this behavior is the same discussed for the hysteresis loops evolution.

\section{CONCLUSIONS}

The effect of different annealing time on the structure and magnetic properties of the samples prepared by LFZ technique were investigated by SEM, XRD and magnetic measurements. It has been found that the annealing time affected the morphology of the samples. XRD results indicate that annealing time do not make a significant difference between the samples. The magnetic hysteresis curves indicated that the superconducting properties of samples start to decrease for annealing times above $96 \mathrm{~h}$. The best calculated $\mathrm{J}_{\mathrm{c}}$ values have been obtained for samples annealed for $96 \mathrm{~h}$, indicating that it is the optimum annealing time to maximize superconducting properties of LFZ grown samples.

\section{ACKNOWLEDGEMENTS}

M. A. Madre acknowledges the MINECO-FEDER (Project MAT2011-22719) for financial support.

M. A. Madre and A. Sotelo acknowledge the MICINN-FEDER (Project MAT200800429) and the Universidad de Zaragoza (Project UZ2011-TEC-03) for financial support.

\section{References:}

[1] Michel, C., Hervieu, M., Borel, M., Grandin, A., Deslandes, F., Provost, J., Raveau, B.: Z. Phys. B 68, 421 (1987) 
[2] Maeda, H., Tanaka,Y., Fukutomi,M., Asano,T.: Jpn. J. Appl. Phys. 27, L209, (1988)

[3] Abou-Aly, A. I., Abdel Gawad, M. M. H., Awad, R., G-Eldeen, I.: J. Supercond. Nov. Magn. 24, 2077 (2011)

[4] Cyrot, M., Pavuna, D.: Introduction to Superconductivity and High-Tc Materials. Word Scientific, Singapore 249 (1995)

[5] Huang, Y. B., de la Fuente, G. F., Sotelo, A., Ruiz, M. T., Larrea, A., Angurel, L. A., Navarro, R.: Solid State Ionics 63-65, 889 (1993)

[6] Knauf, N., Harwischmacher J., Miller R., Borowski R., Rodeu B., Wohllebreu D.: Physica C 173, 414 (1991)

[7] Carrasco, M. F., Costa, F. M., Silva, R. F., Gimeno, F., Sotelo, A., Mora, M., Diez, J. C., Angurel, L. A.: Physica C 415, 163 (2004)

[8] Elschner, S., Boch, J., Brommer, G., Hermann, P.: IEEE Trans. Magn. 21, 2724 (1996)

[9] Coskun A., Ekicibil, A., Ozcelik, B., Chin.Phys.Lett. 19/12, 1863 (2002)

[10] Huang, C. J., Tseng, T.Y., Heh, T. S., Chen, F. H, Jong, W. S., Fran, Y. S., Shiau, S. M.: Solid State Commun. 72, 563 (1989)

[11] Liu, R. S., Wang, W. N., Chang, C. T., Wu, P. T.: Jpn. J. Appl. Phys. 28, L2155 (1989)

[12] Asaka, T., Okazawa, Y., Hirayama, T., Tachikawa, K.: Jpn. J. Appl. Phys. 29, L280 (1990)

[13] Mora, M., Sotelo, A., Amaveda, H., Madre, M. A., Diez, J. C., Angurel, L. A., de la Fuente, G. F.: Bol. Soc. Esp. Ceram. V. 44, 199 (2005)

[14] Sotelo, A., de la Fuente, G. F., Lera, F., Beltran, D., Sapiña, F. Ibañez, Beltran, R.A. Bermejo, M. R.: Chem. Mater. 5, 851 (1993)

[15] Sotelo, A., Szillat, H., Majewski, P., Aldinger, F.: Supercond. Sci. Technol. 10, 717 (1997)

[16] Sotelo, A., Peña, J. I., Angurel, L. A., Diez, J. C., Ruiz, M. T., de la Fuente, G. F., Navarro, R.: J. Mater. Sci. 32, 5679 (1997)

[17] Madre, M. A., Amaveda, H., Mora, M., Sotelo, A., Angurel, L. A., Diez, J. C.: Bol. Soc. Esp. Ceram. V. 47, 148 (2008)

[18] Sotelo, A., Madre, M. A., Rasekh, Sh., Diez, J. C., Angurel, L. A.: Adv. Appl. Ceram. 108, 285 (2009)

[19] Garnier, V., Caillard, R., Sotelo, A., Desgardin, G.: Physica C 319, 197 (1999) 
[20] Marinel, S., Bourgault, D., Belmont, O., Sotelo, A., Desgardin, G.: Physica C 315, 205 (1999)

[21] Huang, Y. B., de la Fuente, G. F., Sotelo, A., Badia, A., Lera, F., Navarro, R., Ibañez, R., Beltran, D., Sapiña, F., Beltran, A.: Physica C 185-189, 2401 (1991)

[22] Sotelo, A., Mora, M. A., Amaveda, H., Diez, J. C., Angurel, L. A., Mayoral, M. C.: Bol. Soc. Esp. Ceram. V. 45, 228 (2006)

[23] Özkurt, B., Madre, M. A., Sotelo, A., Yakıncı, M.E., Özçelik, B.: J. Supercond. Nov. Magn. 25, 799 (2012)

[24] Sotelo, A., Guilmeau, E., Madre, M. A., Marinel, S., Diez, J. C., Prevel, M.: J. Eur. Ceram. Soc. 27, 3697 (2007)

[25] de la Fuente, G. F., Ruiz, M. T., Sotelo, A., Larrea, A., Navarro, R.: Mater. Sci. Eng. A 173, 201 (1993)

[26] Sotelo, A., Madre, M. A., Diez, J. C., Rasekh, Sh., Angurel, L. A., Martinez, E.: Supercond. Sci. Technol. 22, 034012 (2009)

[27] de la Fuente, G. F., Sotelo, A., Huang, Y., Ruiz, M. T., Badia, A., Angurel, L. A., Lera, F., Navarro, R., Rillo, C., Ibañez, R., Beltran, D., Sapiña, F., Beltran, A.: Physica C 185-189, 509 (1991)

[28] Sotelo, A., Rasekh, Sh., Madre, M. A., Diez, J. C.: J. Supercond. Nov. Magn. 24, 19 (2011)

[29] Lide, D. R.: CRC Handbook of Chemistry and Physics. CRC Press/Taylor and Francis, Boca Raton, FL (2010)

[30] Sotelo, A., Angurel, L. A., Ruiz, M. T., Larrea, A., Lera, F., de la Fuente, G. F.: Solid State Ionics 63-65, 883 (1993)

[31] de la Fuente, G. F., Diez, J. C., Angurel, L. A., Peña, J. I., Sotelo, A., Navarro, R.: Adv. Mater. 7, 853 (1995)

[32] Triscone, G., Genoud, J.-Y., Graf, T., Junod, A., Muller, J.: Physica C 176, 247 (1991)

[33] Sotelo, A., Mora, M., Madre, M. A., Diez, J. C., Angurel, L. A., de la Fuente, G. F.: J. Eur. Ceram. Soc. 25, 2947 (2005)

[34] Mora, M., Sotelo, A., Amaveda, H., Madre, M. A., Diez, J. C., Capel, F., LópezCepero, J. M.: J. Eur. Ceram. Soc. 27, 3959 (2007)

[35] Bean, C.P. Phys.Rev.Lett. 8, 250 (1962) 


\section{FIGURE CAPTIONS:}

Fig.1. Schematic illustration of LFZ technique showing the different zones found in the samples processing.

Fig.2. SEM images of transversal fractured samples A, B, C and D.

Fig.3. XRD patterns of the samples, $+\mathrm{Bi}-2212, * \mathrm{CaBi}_{2} \mathrm{O}_{4}$

Fig.4. Magnetic hysteresis curves obtained for the different samples at $10 \mathrm{~K}$.

Fig.5. Magnetic moment as a function of temperature for different sintering times

Fig.6. Calculated $\mathrm{J}_{\mathrm{c}}$ values for the different samples, at $10 \mathrm{~K}$ 


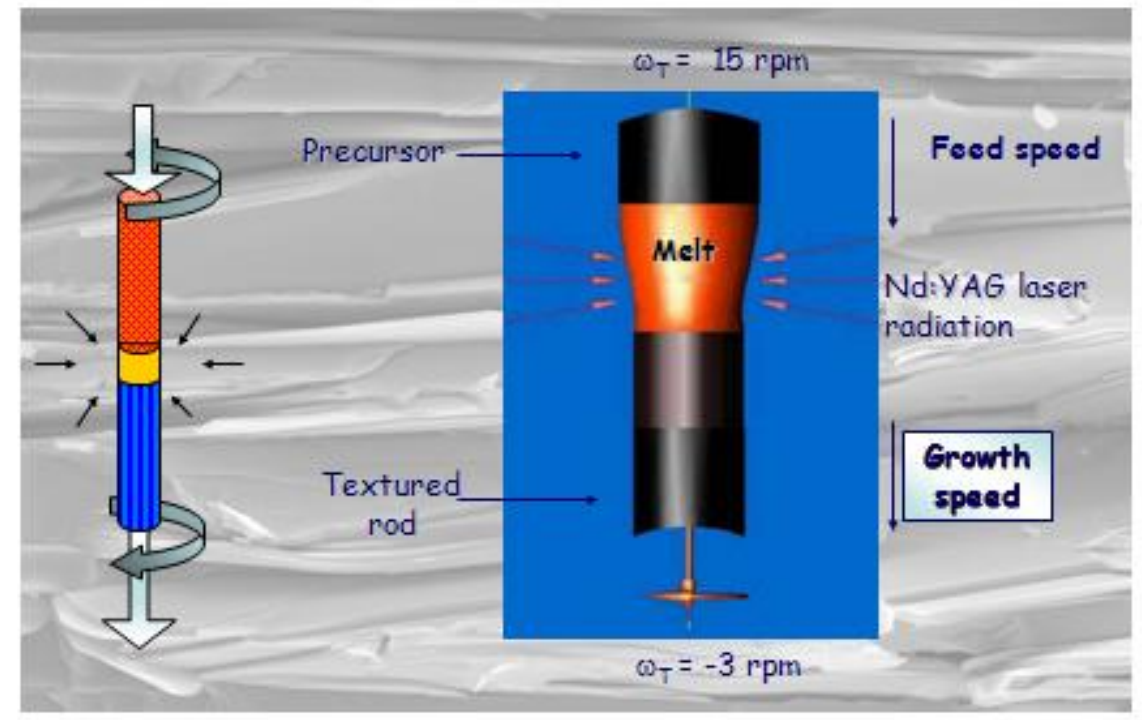

Fig.1 


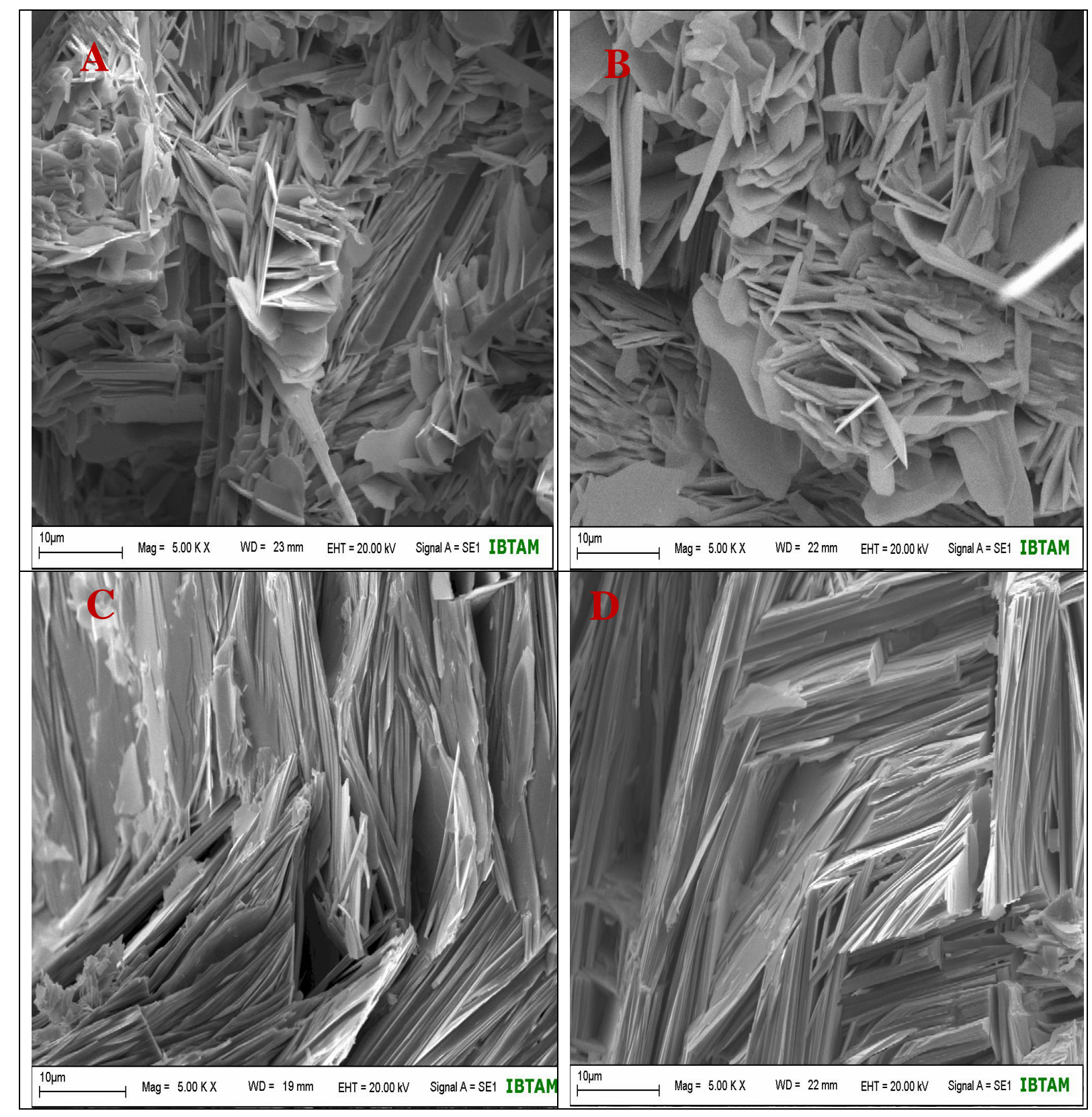

Fig.2 


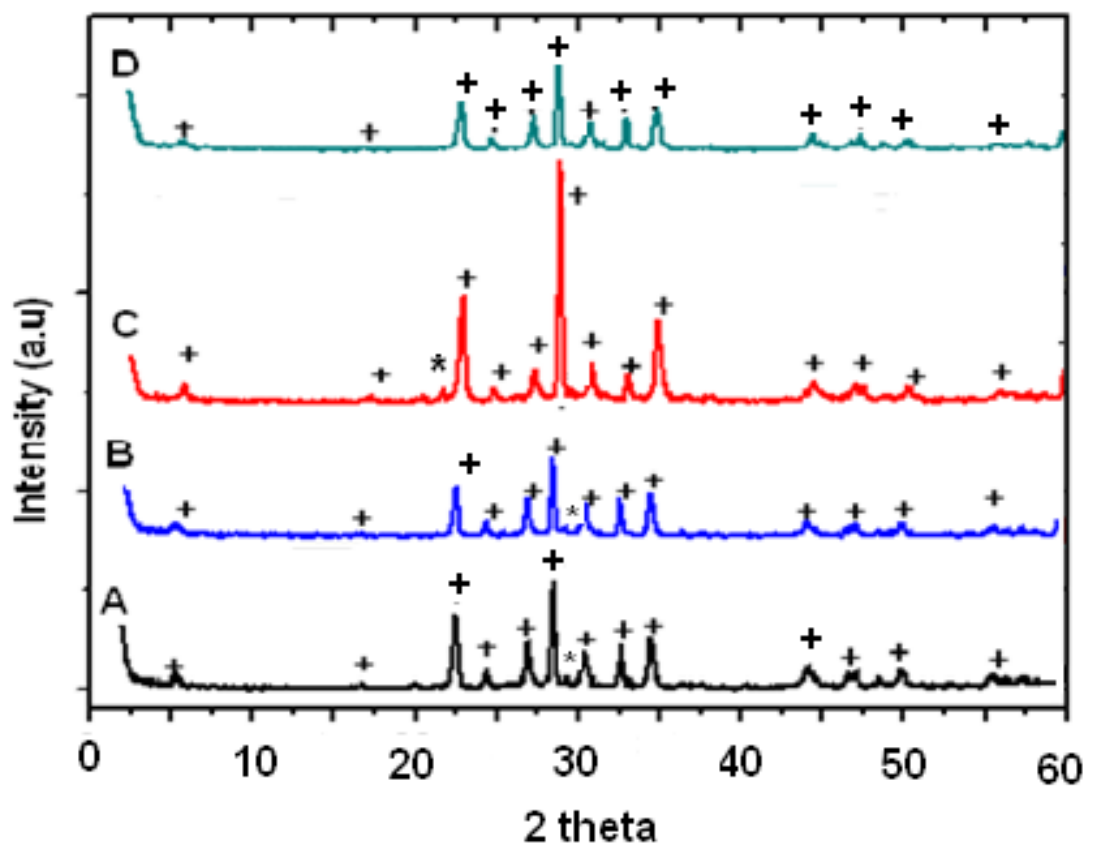

Fig.3

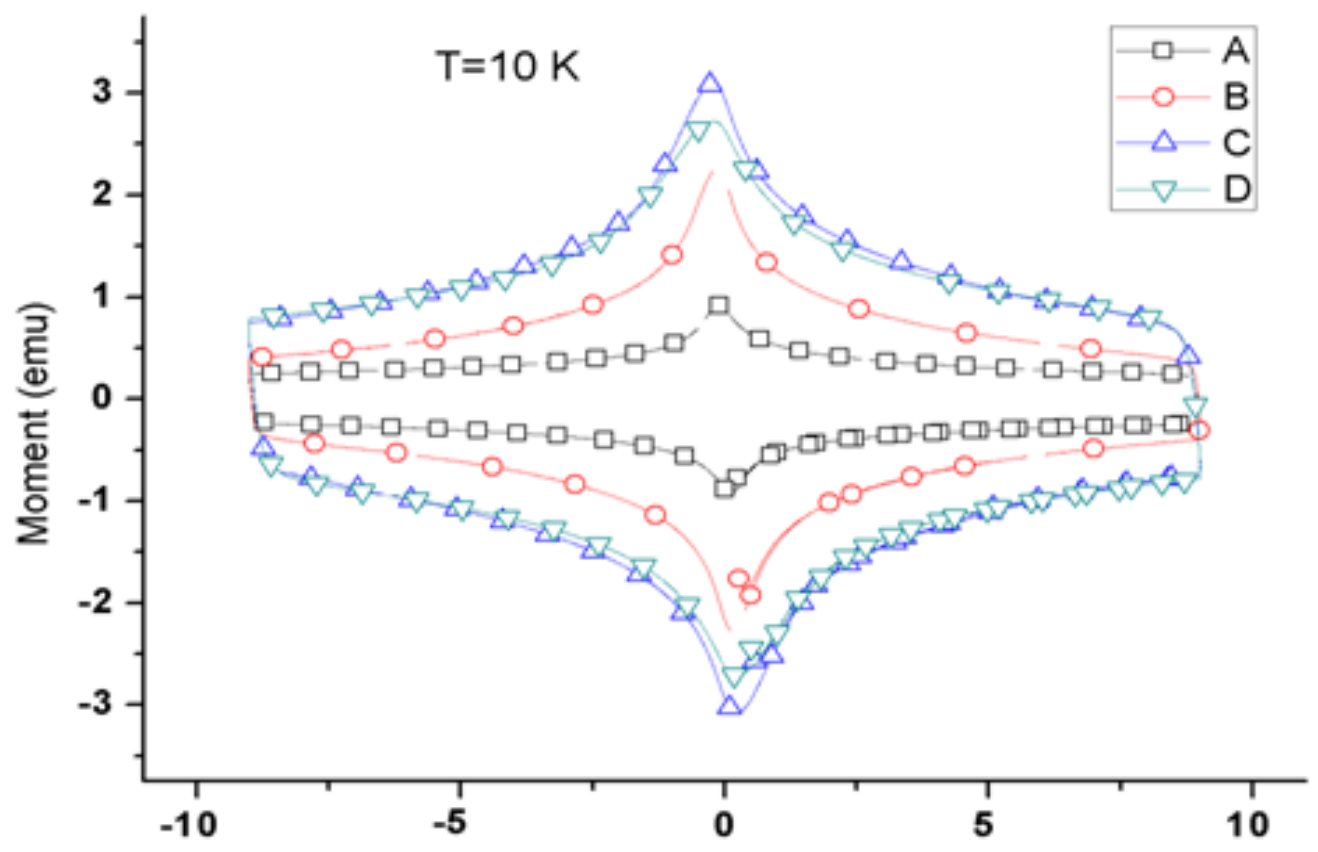

Field (T)

Fig. 4 


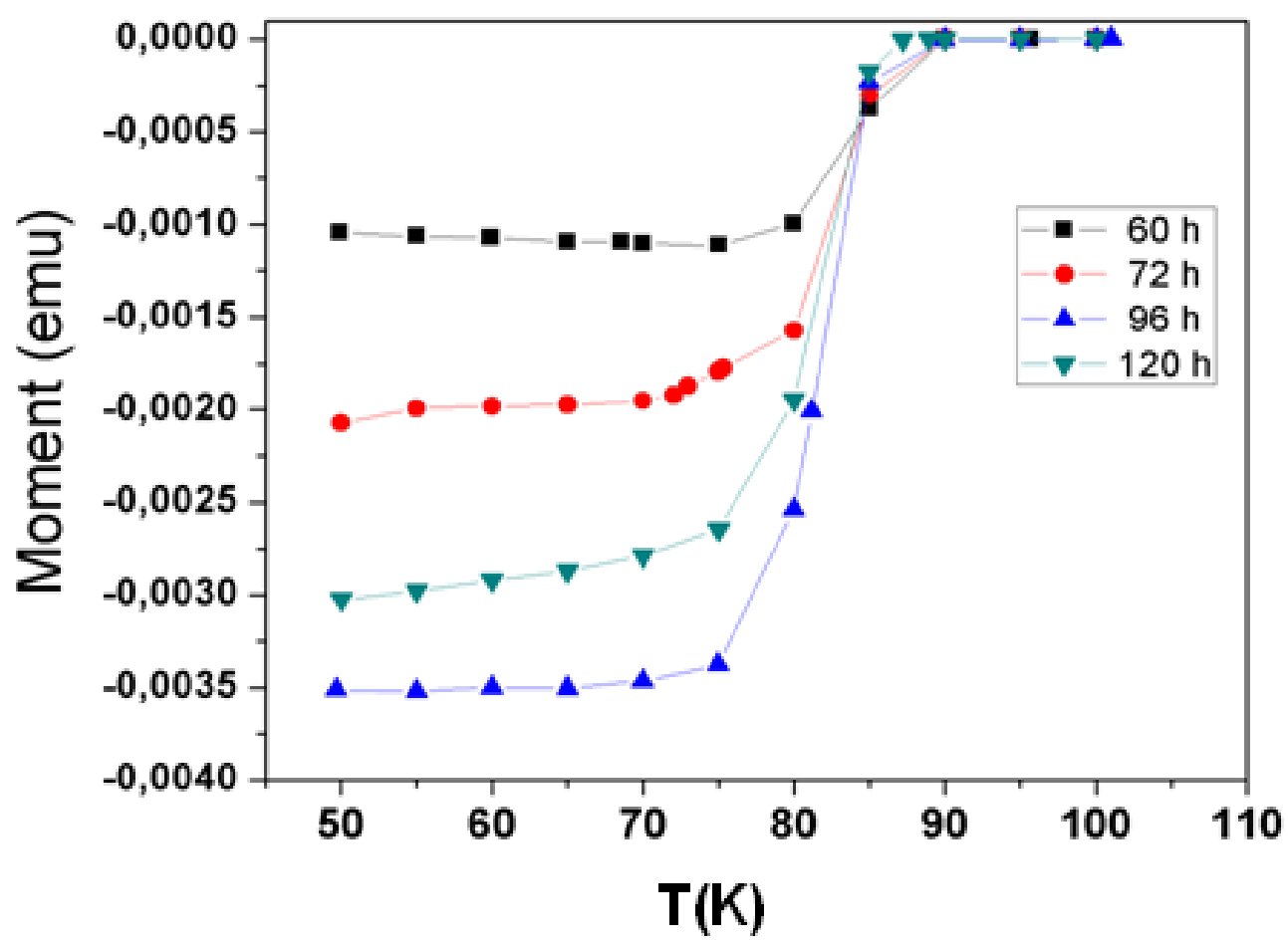

Fig. 5

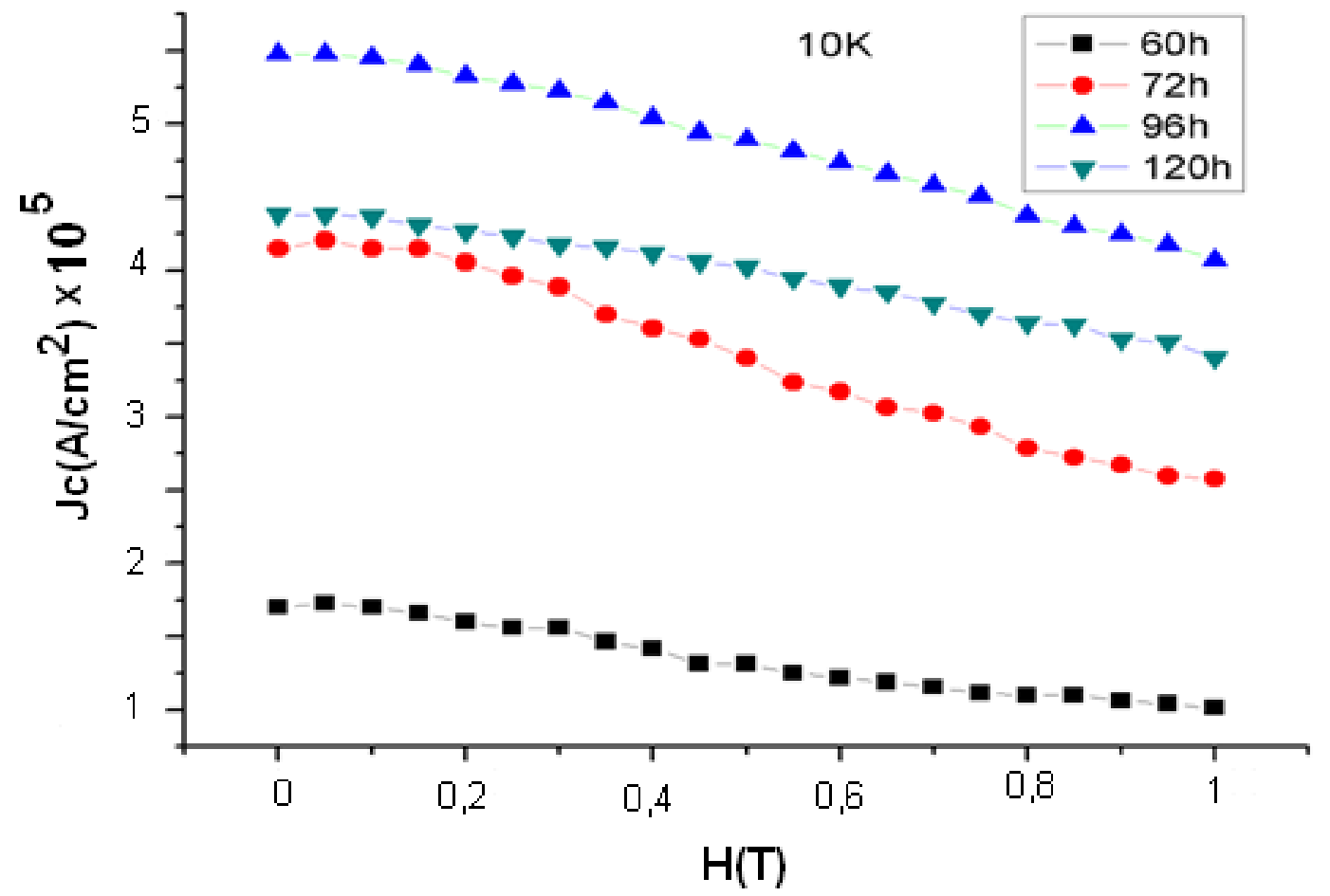

Fig. 6 